\title{
Research and Application of Cold Productivity Formula of Horizontal Well in the Power-Law Fluid Heavy Oil Reservoir
}

\author{
Gongchang Wang *, Yingxian Liu and Zongbin Liu \\ Tianjin Branch of CNOOC Ltd., Tianjin, China
}

Considering the rheological properties of fluid, reservoir heterogeneity, and eccentricity factor, the productivity formula of horizontal well for the power-law fluid heavy oil reservoir is derived by transforming the three-dimensional seepage problem into a two-dimensional seepage problem. The heavy oil production calculated by this formula is in good agreement with the actual production in the offshore oil field. Then, the influencing factors of production are analyzed, and the results show that the power-law index has the greatest influence on production. When the power-law index is less than 0.8 , the production increases slowly with the power-law index and when it is greater than 0.8 , the

Edited by: Xun Zhong,

Yangtze University, China

Reviewed by: Xingbang Meng,

China University of Petroleum (Huadong), China Daigang Wang, China University of Petroleum, China

${ }^{*}$ Correspondence: Gongchang Wang wanggch12@cnooc.com.cn

Specialty section: This article was submitted to Carbon Capture, Utilization and Storage,

a section of the journal Frontiers in Energy Research

Received: 10 October 2021 Accepted: 22 October 2021 Published: 15 November 2021

Citation:

Wang G, Liu Y and Liu Z (2021)

Research and Application of Cold Productivity Formula of Horizontal Well

in the Power-Law Fluid Heavy

Oil Reservoir

Front. Energy Res. 9:792427. doi: 10.3389/fenrg.2021.792427 production increases faster. The power-law index has a greater impact on production for higher production pressure differential and longer horizontal well. Anisotropy has significant influence on the production. When the value of $K_{h} / K_{v}$ is less than 10 , the production decreases rapidly with the $K_{h} / K_{v}$; after the value of $K_{h} / K_{v}$ is greater than 10 , the production decreases slower. Eccentricity has trivial impact on the production.

Keywords: heavy oil reservoir, power-law fluid, horizontal well, productivity, cold production

\section{INTRODUCTION}

Heavy oil reservoirs are widely spread all over the world and has huge reserves in China, which provides an important guarantee for the security of Chinese energy supply (Li et al., 2016; Wu et al., 2016; Jiang et al., 2019; Jiang et al., 2021). It is shown that the partial heavy oil is a power-law fluid and exhibits non-Newtonian fluid characteristics during the flow. Non-Newtonian fluids are defined as those fluids that exhibit a power-law proportion between shear stress and strain rate.

Horizontal well can increase the production of the heavy oil reservoir, reduce water content, and improve oilfield development efficiency. At present, the research on heavy oil reservoir productivity focuses mainly on vertical and horizontal well thermal recovery, while the research on horizontal well cold recovery production is rare or does not consider the impact of reservoir anisotropy and eccentricity (Song and Liu, 2000; Lin et al., 2016; Shen et al., 2016; Zhang et al., 2016a; Zhang et al., 2018). Cold production means that the heavy oil is developed by the natural reservoir energy. Compared to the thermal recovery method, the heavy oil reservoir cold recovery method has the benefits of lower energy consumption and better economic advantages.

In this article, the productivity formula of horizontal well for the power-law fluid heavy oil reservoir is derived, considering heavy oil rheological characteristics, reservoir asymmetry, and eccentric factors and is verified by the actual production of an offshore oilfield. The influence of different factors on the horizontal well production is also analyzed. 


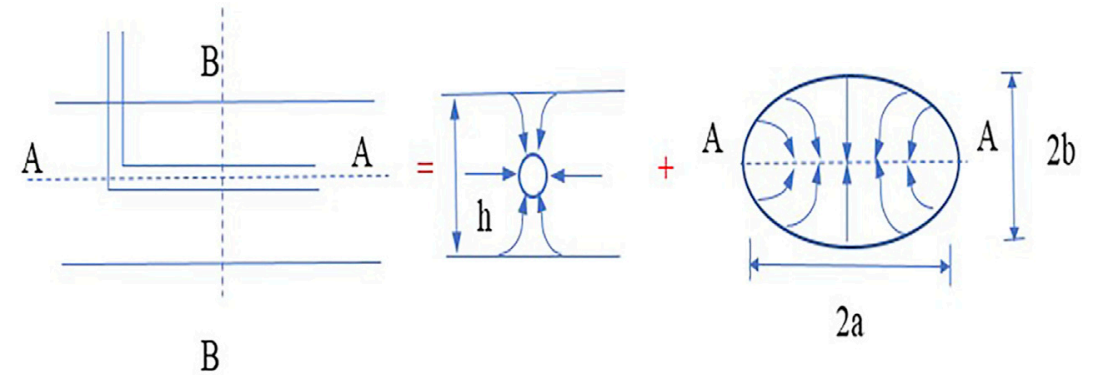
A horizontal wel
B outer space
C inner space

FIGURE 1 | Schematic diagram of transforming a three-dimensional seepage problem into two two-dimensional seepage problems.

\section{DERIVATION OF THE HORIZONTAL WELL PRODUCTIVITY FORMULA OF THE POWER-LAW FLUID HEAVY OIL RESERVOIR}

The formula for calculating the apparent viscosity of power-law heavy oil flowing in porous media is given by the following equation (Vongvuthipornchai and Raghavan, 1987; Lv et al., 2002; Zhang et al., 2016b):

$$
\begin{gathered}
\mu_{b}=\mu_{e f f} \cdot v^{n-1} \\
\mu_{e f f}=\frac{H}{12}(9+3 / \mathrm{n})^{n} \cdot\left(1.5 \times 10^{5} K \Phi\right)^{\frac{1-n}{2}}
\end{gathered}
$$

where $v$ is the seepage velocity, $\mathrm{m} / \mathrm{s} ; K$ is the porous medium permeability, $\mu \mathrm{m}^{2} ; \mu_{\mathrm{b}}$ is the apparent viscosity of heavy oil, $\mathrm{mPa}$; $n$ is the power-law index; $\Phi$ is the porosity of porous media; $H$ is the consistency coefficient, $\mathrm{mPa} \mathrm{n}^{\mathrm{n}}$ and; $\mu_{e f f}$ is the bed factor of the formation.

Assuming a horizontal well produced in the heavy oil reservoir, the horizontal well length is $L$, the eccentricity is $\sigma$, and the wellbore radius is $r_{w}$. The flowing bottom hole pressure is $P_{w}$ when at stable production. The reservoir thickness is $h$, with the reservoir supply radius of $r_{e}$, and the pressure of reservoir boundaries of $P_{E}$. The fluid in formation is incompressible, and the influence of gravity and capillary force is ignored.

As the horizontal well is produced, the fluid is at the threedimensional space seepage state. According to Joshi's formula, the three-dimensional seepage problem of the horizontal well can be simplified into two interrelated two-dimensional seepage problems, as shown in Figure 1. The inner zone is the radial flow on the plane perpendicular to the horizontal well axis, and the outer zone is the flow of the fluid far away from the horizontal well, and can be approximated to the flow on the horizontal plane with an oval drainage area.

\subsection{Derivation of the Outer Zone Productivity Formula}

According to the Joukowski transformation, the elliptical area with the major half-axis of a and minor half-axis of $b$ can be transformed into a circular area with a radius of $(\mathrm{a}+\mathrm{b})$ and well diameter of $0.5 \mathrm{~L}$. According to the Darcy formula, the production at steady state is as follows:

$$
v^{n}=\left(\frac{q_{1} B_{o}}{2 \pi r}\right)^{n}=\frac{k}{\mu_{e f f}} \frac{d p}{d r},
$$

where $B o$ is the oil volume factor and $q_{1}$ is the inner zone production, $\mathrm{m}^{3} / \mathrm{d}$.

Equation 4 is obtained by transforming Eq. 3:

$$
\int_{0.5 L}^{a+b}\left(\frac{q_{1} B_{o}}{2 \pi}\right)^{n} \frac{1}{r^{n}} d r=\frac{k}{\mu_{e f f}} \int_{p_{w}}^{p_{e}} d p .
$$

Integrating Eq. 4 can get the following equation:

$$
q_{1}^{n}=\frac{k\left(p_{e}-p_{w}\right)}{\mu_{e f f}\left(\frac{B_{o}}{2 \pi}\right)^{n} \frac{1}{1-n}\left[(a+b)^{1-n}-(0.5 L)^{1-n}\right]} .
$$

Based on Eq. 5, the outer zone productivity formula is given by the following formula:

$$
q_{H}^{n}=\left(q_{1} \cdot h\right)^{n}=\frac{k\left(p_{e}-p_{w}\right)}{\mu_{e f f}\left(\frac{B_{o}}{2 \pi h}\right)^{n} \frac{1}{1-n}\left[(a+b)^{1-n}-(0.5 L)^{1-n}\right]} .
$$

Then, the seepage resistance of the outer zone is given by the following equation:

$$
\mathrm{R}_{\mathrm{fH}}=\frac{\Delta p}{q_{H}}=\frac{\Delta p}{\left\{\frac{k\left(p_{e}-p_{w}\right)}{\mu_{e f f}\left(\frac{B_{0}}{2 \pi h}\right)^{n} \frac{1}{1-n}\left[(a+b)^{1-n}-(0.5 L)^{1-n}\right]}\right\}^{\frac{1}{n}} .}
$$

\subsection{Inner Zone Productivity Formula}

By the transformation of $\xi=\left(1-\mathrm{e} \frac{-\pi z}{h}\right) \times\left(1-\mathrm{e} \frac{\pi z}{h}\right)$, the inner zone is equal to a unit circle region on the $\xi$ plane, the well eccentricity is changed to $\mathrm{d}$, where $d=\frac{2 \sigma}{h}$. The radius of the wellbore is transformed to $\xi_{w}=\frac{2 r_{w}}{h}$.

Based on $\eta=\frac{\xi-\xi_{0}}{1-\overline{\xi_{0} \xi}}$, it is transformed into a unit circle with a well located at the origin of coordinates. On the $\eta$ plane, the well radius is $\rho_{w}=\frac{\xi_{w}}{1-d^{2}}=\frac{2 r_{w} / h}{1-(2 \sigma / h)^{2}}$.

The productivity formula of the inner zone is given by the following equation: 


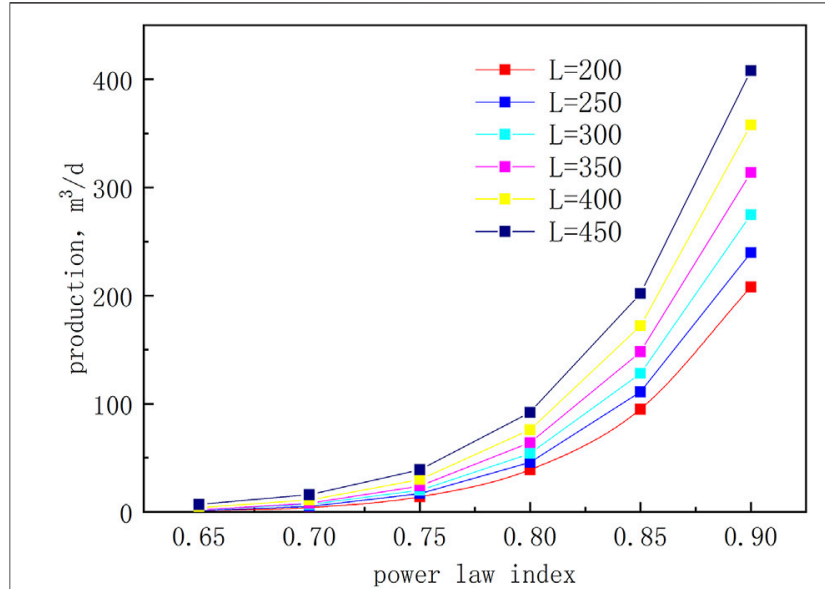

FIGURE 2 | Influence of power law index on production under different horizontal well lengths.

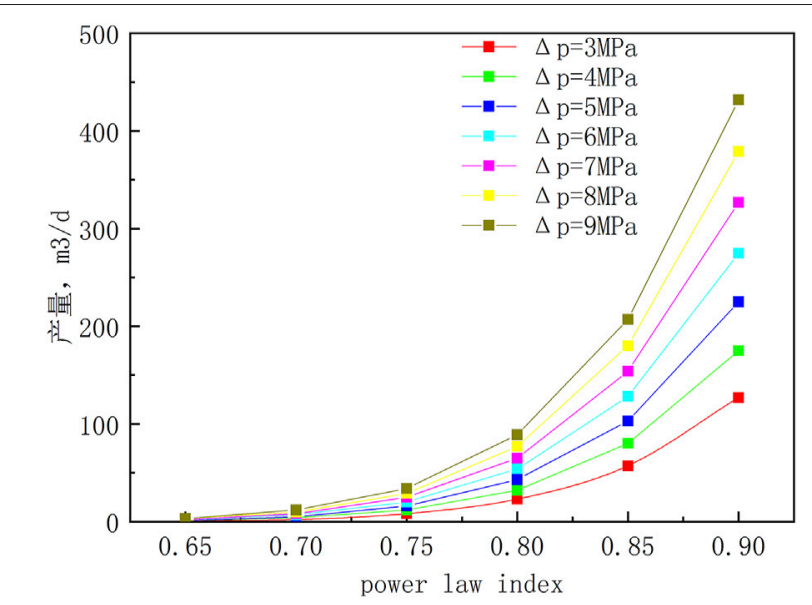

FIGURE 3 | Influence of power law index on production under different production pressure differences.

$$
q_{H}^{n}=\left(q_{1} \cdot L\right)^{n}=\frac{k\left(p_{e}-p_{w}\right)}{\mu_{e f f}\left(\frac{B_{o}}{2 \pi L}\right)^{n} \frac{1}{1-n}\left(1-\rho_{w}^{1-n}\right)} .
$$

Then the seepage resistance in the inner zone is given by the equation:

$$
\mathrm{R}_{\mathrm{fV}}=\frac{\Delta p}{q_{V}}=\frac{\Delta p}{\left\{\frac{k\left(p_{e}-p_{w}\right)}{\mu_{e f f}\left(\frac{B_{o}}{2 \pi L}\right)^{n} \frac{1}{1-n}\left[1-\rho_{w}^{1-n}\right]}\right\}^{\frac{1}{n}} .}
$$

According to the principle of equivalent seepage resistance, the production of the horizontal well can be written as follows:

$$
\begin{aligned}
Q_{H} & =\frac{\Delta p}{\mathrm{R}_{\mathrm{fH}}+\mathrm{R}_{\mathrm{fV}}} \\
& =\frac{1}{\left\{\frac{k\left(p_{e}-p_{w}\right)}{\mu_{e f f}\left(\frac{B_{o}}{2 \pi h}\right)^{n} \frac{1}{1-n}\left[(a+b)^{1-n}-(0.5 L)^{1-n}\right]}\right\}^{-\frac{1}{n}}+\left\{\frac{k\left(p_{e}-p_{w}\right)}{\mu_{e f f}\left(\frac{B_{o}}{2 \pi L}\right)^{n} \frac{1}{1-n}\left[1-\rho_{w}^{1-n}\right]}\right\}^{-\frac{1}{n}}} .
\end{aligned}
$$

The following equation can be obtained after the simplification of Eq. 10:

$$
Q_{H}=\frac{\left[\frac{k\left(p_{e}-p_{w}\right)}{\mu_{e f f}\left(\frac{B_{o}}{2 \pi h}\right)^{n}}\right]^{\frac{1}{n}}}{\left\{\frac{1}{1-n}\left[(a+b)^{1-n}-(0.5 L)^{1-n}\right]\right\}^{\frac{1}{n}}+\left[\left(\frac{h}{L}\right)^{n} \frac{1}{1-n} 1-\left(\frac{2 r_{w} / h}{1-(2 \sigma / h)^{2}}\right)^{1-n}\right]}
$$

Considering the reservoir anisotropy, $h$ is changed to $\beta \mathrm{h}$ according to the Muskat correction method,where $\beta=\sqrt{K_{h} / K_{V}}$.

Then, Eq. 11 is transformed to Eq. 12 as follows:

$$
Q_{H}=\frac{\left[\frac{\sqrt{K_{h} K_{V}}\left(p_{e}-p_{w}\right)}{\mu_{e f f}\left(\frac{B_{o}}{2 \pi \beta h}\right)^{n}}\right]^{\frac{1}{n}}}{\left\{\frac{1}{1-n}\left[(a+b)^{1-n}-(0.5 L)^{1-n}\right]\right\}^{\frac{1}{n}}+\left(\frac{\beta h}{L}\right)^{n} \frac{1}{1-n}\left[1-\left(\frac{2 r_{w} / \beta h}{1-(2 \sigma / \beta h)^{2}}\right)^{1-n}\right]}
$$

\section{VERIFICATION OF THE HORIZONTAL WELL PRODUCTIVITY FORMULA}

The edge heavy oil reservoir of the SZ oilfield is a typical powerlaw fluid heavy oil reservoir with the horizontal permeability of $3 \mu \mathrm{m}^{2}$, vertical permeability of $0.3 \mu \mathrm{m}^{2}$, and porosity of 0.4 . The reservoir thickness is $7 \mathrm{~m}$, the supply radius is $334 \mathrm{~m}$, and the reservoir pressure is $12.8 \mathrm{MPa}$. It is now under cold production with horizontal wells and achieves a high production rate. The wellbore radius is $0.1 \mathrm{~m}$, the length is $300 \mathrm{~m}$, and the eccentricity is 1.0. The volume coefficient of crude oil is 1.09 , the power-law index is 0.8 , and the consistency coefficient is $60.6 \mathrm{mPa} \mathrm{s}^{\mathrm{n}}$.

Using the basic parameters of the aforementioned reservoir, the productivity formula deduced in this article is used to calculate the production when the production pressure difference is $6 \mathrm{MPa}$ and is compared with the actual production. The calculated production is 46 , and the actual production of the horizontal well is $48 \mathrm{~m}^{3} / \mathrm{d}$, with an error of $4.2 \%$, indicating that the cold production formula of horizontal wells derived in this article has high accuracy and can be used to evaluate the potential of the reservoir.

\section{STUDY ON INFLUENCING FACTORS OF HORIZONTAL WELL PRODUCTION}

Using the aforementioned reservoir basic data, the influencing factors of cold production of horizontal wells in power-law fluid heavy oil reservoirs were studied.

\subsection{Influence of the Power-Law Index on Production}

The horizontal well production under different power-law indices is studied by changing the power-law indices. Figures 2, 3 show the influence of the power-law index on horizontal well 


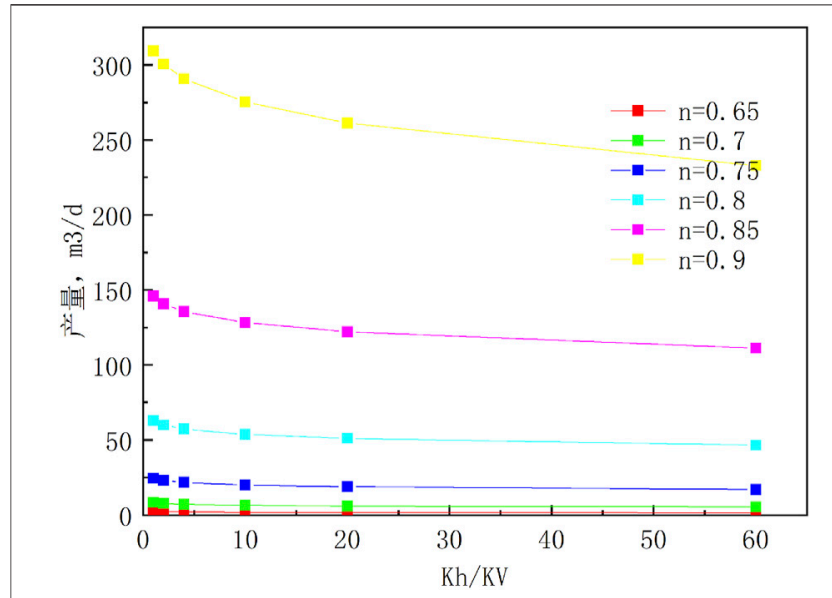

FIGURE 4 | Influence of anisotropy of on yield with different power law indices.

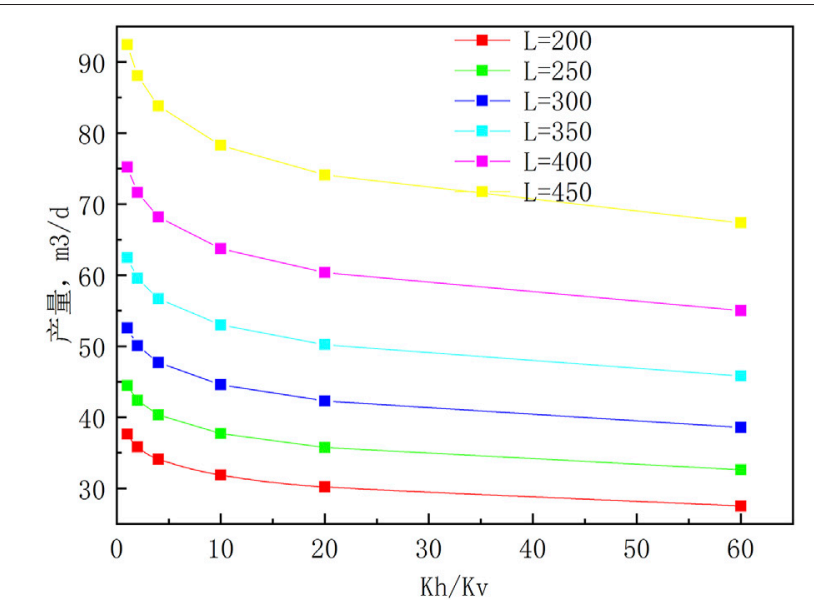

FIGURE 5 | Effect of anisotropy of on production with different horizontal well lengths.

production under different horizontal well lengths and different production pressure differences, respectively.

As can be seen from Figures 2, 3, for horizontal wells of a certain length, production increases with the increase of the power-law index. When the power-law index is less than 0.8 , production increases slowly; after the power-law index reaches a value greater than 0.8 , production rapidly increases. The longer the horizontal well, the higher the production and the greater the increase of production with the power-law index. The larger the production pressure difference, the higher the production, and the influence of the power-law index on the production is more obvious.

\subsection{Effect of Reservoir Anisotropy on Production}

The effect of anisotropy on horizontal well production was studied by changing the ratio of horizontal permeability to

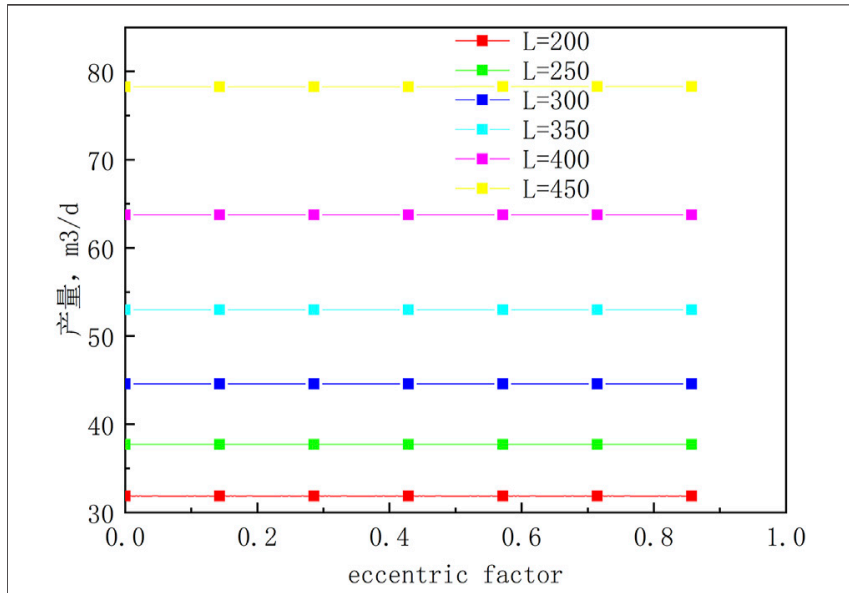

FIGURE 6 | Influence of eccentricity on production with different horizontal well lengths.

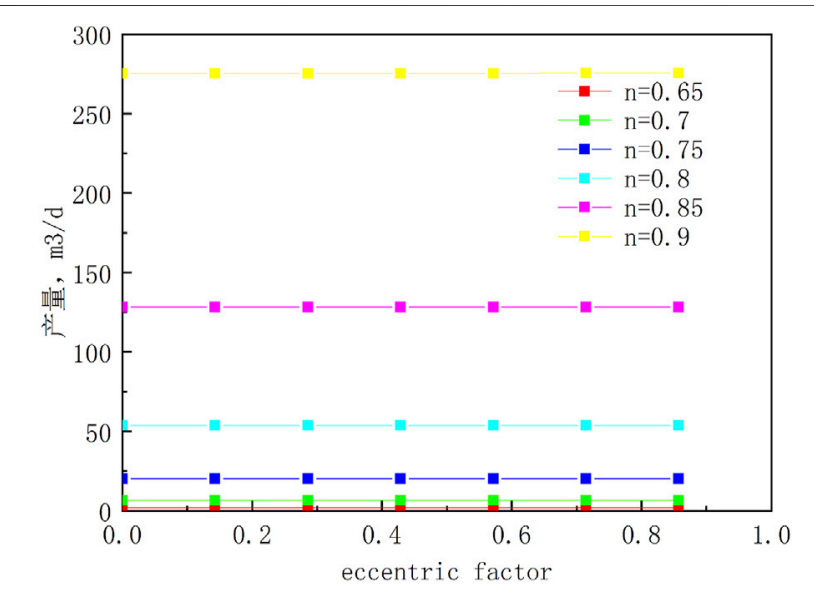

FIGURE 7 | Influence of eccentric factor on production with different power law indices.

vertical permeability. Figures 4, 5 show the effects of anisotropy on production under different power-law indices and different horizontal well lengths, respectively.

It can be seen from Figures 4, 5 that anisotropy has a great influence on the production of horizontal wells. With the increase of anisotropy, that is, when the $\mathrm{K}_{\mathrm{h}} / \mathrm{K}_{\mathrm{v}}$ ratio increases, the production of horizontal wells decreases. When $\mathrm{K}_{\mathrm{h}} / \mathrm{K}_{\mathrm{v}}$ is less than 10 , the production decreases rapidly, and after $\mathrm{K}_{\mathrm{h}} / \mathrm{K}_{\mathrm{v}}$ is more than 10, the production decreases slowly. The effect of anisotropy on production is related to the power-law index and horizontal well length. With the increase of power-law index and horizontal well length, the horizontal well production decreases more with the increase of anisotropy and is more sensitive to anisotropy.

\subsection{The Influence of Eccentricity on Production}

The influence of eccentricity on horizontal well production is studied by changing the magnitude of eccentricity $\sigma$. The eccentric factor $\lambda$ is 
defined as $\lambda=\sigma /(\mathrm{H} / 2)$ (Liu et al., 2019). The eccentric factor is proportional to eccentricity; the greater the eccentricity, the greater the eccentricity factor. Figures 6, 7, show the influence of eccentricity on production under different power-law indices and different horizontal well lengths, respectively.

It can be seen from Figures 6, 7 that when the value of eccentricity factor is changed, the production of horizontal wells with different power-law indices and different horizontal well lengths basically does not change, indicating that eccentricity has little influence on the production of horizontal wells in power-law fluid heavy oil reservoirs and therefore can be ignored in production calculation.

\section{CONCLUSION}

1) Considering the rheological properties of fluid, reservoir heterogeneity and eccentricity factor, and combined with the characteristics of the horizontal well seepage field, the horizontal well productivity formula is derived for the powerlaw fluid heavy oil reservoir.

2) Based on the actual reservoir parameters, the deduced productivity formula is used to calculate the production of horizontal wells. The error between the calculated results and the actual production is small, which verifies the accuracy and practicability of the production formula.

3) The horizontal well production is very sensitive to the power-law index. When the power-law index is greater

\section{REFERENCES}

Chen, Y., and Zou, C. (2009). Derivation Comparison and Application of Horizontal Well Production Formula Considering the Effects of Anisotropy and Eccentricity[J]. Xinjiang Pet. Geology. 30 (4), 486-489.

Jiang, P., Zhou, X., and Yuan, Y. (2021). Adaptability Analysis of Polymer Flooding in Mid-low Permeability Heavy Oil Reservoirs[J]. J. China Univ. Pet. (Edition Nat. Science) 45 (3), 166-170.

Jiang, Y., Song, Z., and Zhao, Z. (2019). Synthesis and Performance Evaluation of a Novel Viscosity Reducing Agent Used for $\mathrm{CO}_{2}$ Compound Huff and Puff in the Heavy Oil Reservoir of the Subei Oilfield[J]. Oil Drilling Prod. Tech. 42 (3), 351-355.

Li, W., Liu, P., and Wu, Y. (2016). A Mathematicalmodel for Foamy-Oil Flow in Heavy Oil Reservoirs[J]. Pet. Geology. Recovery Efficiency 23 (2), 108-114.

Lin, L. I., Luo, D., and Tao, B. (2016). Water Cut Rising Performance of Horizontal wells in Thin-Bed Heavy Oil Reservoir with Edge-Bottom Water in Panyu Oilfield[J]. Pet. Geology. Recovery Efficiency 23 (3), 106-110.

Liu, W., Tong, D., and Zhang, S. (2019). A New Method for Calculating Productivity of Horizontal Well in Low-Permeability Heavy Oil Reservoir [J]. Acta Petrolei Sinicam2010 31 (3), 458-462.

Lv, C., Wang, J., and Sun, Z. (2002). An Experimental Study on Threshold Pressure Gradient of Fluids Flow in Low Permeability sandstone Porous Media[J]. Pet. Exploration Dev. 29 (2), 86-89.

Shen, F., Chengsong, L., and Huang, S. (2016). Calculation of Sweep Efficiency for Water Flooding Development of Conventional Heavy Oil Using the StreamTube Method[J]. Oil Drilling Prod. Tech. 38 (5), 645-649.

Song, F., and Liu, C. (2000). Study of Unsteady Flow of Non-newtonian Power-Law Fluid in Horizontal wells of Low Permeability Reservoir[J]. Well Test. 9 (1), 2-6. than 0.8 , the production increases rapidly with the increase of the power-law index; as the power-law index is less than 0.8 , the production increases slowly. Anisotropy has great influence on the production of horizontal wells. When $\mathrm{K}_{\mathrm{h}}$ / $K_{v}$ is less than 10 , the production decreases rapidly, and after $K_{h} / K_{v}$ reaches a value more than 10 , the production decreases slowly. Eccentricity has trivial effects on the production of horizontal wells. In order to obtain accurate horizontal well production, the influence of fluid rheological parameters and reservoir anisotropy parameters cannot be ignored when calculating production.

\section{DATA AVAILABILITY STATEMENT}

The original contributions presented in the study are included in the article/supplementary material, and further inquiries can be directed to the corresponding author.

\section{AUTHOR CONTRIBUTIONS}

GW contributed to methodology and investigation, YL contributed to writing-original draft preparation, and ZL contributed to writing-review and editing. All authors have read and agreed to the published version of the manuscript.

Vongvuthipornchai, S., and Raghavan, R. (1987). Well Test Analysis of Data Dominated by Storage and Skin: Non-newtonian Power-Law Fluids[R]. SPE 14454.

Wu, Z., Liu, H., and Pang, Z. (2016). Numerical Simulation and Tests of Gas-Foam Assisted Steam Flooding for Heavy Oil Development[J]. Oil Drilling Prod. Tech. 38 (6), 852-858.

Zhang, X, Xie, X, and Li, Y (2016). Optimization model of injection-production parameters for steam stimulation in heavy oil reservoirs of Bohai petroliferous area[J]. Petroleum Geology and Recovery Efficiency 23 (5), 88-92.

Zhang, X, Yang, Z, and Wang, S (2016). A new method for productivity calculation of horizontal wells in power-law heavy oil reservoirs[J]. Petroleum Geology and Engineering 30 (2), 72-74.

Zhang, Y, Liao, X, and Hu, Y (2018). Development models for offshore heavy oil field in high water cut stage[J]. Lithologic Reservoirs 30 (4), 120-126.

Conflict of Interest: Authors GW, YL, and ZL were employed by the Tianjin Branch of CNOOC Ltd.

Publisher's Note: All claims expressed in this article are solely those of the authors and do not necessarily represent those of their affiliated organizations, or those of the publisher, the editors, and the reviewers. Any product that may be evaluated in this article or claim that may be made by its manufacturer is not guaranteed or endorsed by the publisher.

Copyright (c) 2021 Wang, Liu and Liu. This is an open-access article distributed under the terms of the Creative Commons Attribution License (CC BY). The use, distribution or reproduction in other forums is permitted, provided the original author(s) and the copyright owner(s) are credited and that the original publication in this journal is cited, in accordance with accepted academic practice. No use, distribution or reproduction is permitted which does not comply with these terms. 